Ecological Applications, 0(0), 2019, e01968

(C) 2019 by the Ecological Society of America

\section{Estimating historical forest density from land-survey data: a response to Baker and Williams (2018)}

Citation: Levine, C. R., C. V. Cogbill, B. M. Collins, A. J. Larson, J. A. Lutz, M. P. North, C. M. Restaino, H. D. Safford, S. L. Stephens, and J. J. Battles. 2019. Estimating historical forest density from land-survey data: a response to Baker and Williams (2018). Ecological Applications 00(00):e01968. 10.1002/eap.1968

\section{To the Editor:}

In the Western United States, historical forest conditions are used to inform land management and ecosystem restoration goals (North et al. 2009, Stephens et al. 2016). This interest is based on the premise that historical forests were resilient to ecological disturbances (Keane et al. 2018). Researchers throughout the United States have used the General Land Office (GLO) surveys of the late 19th and early 20th centuries to estimate historical forest conditions (Bourdo 1956, Schulte and Mladenoff 2001, Cogbill et al. 2002, Paciorek et al. 2016). These surveys were conducted throughout the United States and represent a systematic, historical sample of trees across a broad geographic area. A challenge of using GLO survey data is the accurate estimation of tree density from sparse witness tree data. Levine et al. (2017) tested the accuracy and precision of four plotless density estimators that can be applied to GLO survey sample data, including the Cottam (Cottam and Curtis 1956), Pollard (Pollard 1971), Morisita (Morisita 1957), and mean harmonic Voronoi density (MHVD; Williams and Baker 2011) estimators. The Cottam, Pollard, and Morisita are count-based plotless density estimators (PDE) and have a history of being applied to GLO data (e.g., Kronenfeld and Wang 2007, Rhemtulla et al. 2009, Hanberry et al. 2012, Maxwell et al. 2014, Goring et al. 2016). The MHVD estimator is an area-based PDE that has been applied by the study's authors to sites in the western United States (Baker 2012, 2014), but had not been independently evaluated. Levine et al. (2017) found that the Morisita estimator was the least biased and most precise estimator for estimating density from GLO survey data, with a relative root mean square error ranging from 0.11 to 0.78 for the six study sites. Levine et al. (2017) also demonstrated the MHVD approach consistently overestimated density from $16 \%$ to $258 \%$ in all six study areas that were analyzed.

Baker and Williams (2018; henceforth B\&W) contend that the major conclusions in Levine et al. (2017; henceforth Levine) are not valid. B\&W's primary criticisms focus on (1) the estimation of diameter at stump height (DSH; $0.30 \mathrm{~m})$ from diameter at breast height $(\mathrm{DBH}$; $1.37 \mathrm{~m}$ ) using taper equations, (2) the simulated sampling regime used to test PDE performance, and (3) the calculation of the mean neighborhood density (MND). Tree size (i.e., DSH) and neighborhood density (i.e., MND) are crucial to the calculation of MHVD since both are used in the projection of Voronoi area (Williams and Baker 2011). To quantify the impact of these criticisms, B\&W modified the published Levine simulation code and then reanalyzed the published data from Levine. B\&W also object to the spatial scale of the analysis, the selection of field sites used to test PDE performance, and the neglect of corroborating evidence. In this response, we address both the quantitative and qualitative critiques of our research, including new simulations that address the issues raised by $\mathrm{B} \& \mathrm{~W}$.

\section{Response to Quantitative Concerns}

\section{Estimation of $\mathrm{DSH}$}

In the supplement of Levine (Appendix S2), we provided results from an analysis using DSH instead of $\mathrm{DBH}$ as the measure of tree size. This supplemental analysis was necessary due to confusion in the methods described in Baker (2014) and subsequently corrected in Baker (2017). B\&W claim that the estimated DSH in Levine underestimated the DSH-to-DBH ratio based on their unpublished field data from Arizona.

We checked our calculations and discovered that we did underestimate DSH by neglecting to account for bark thickness. We corrected this error by applying species-specific, diameter-to-bark-thickness ratios (Reinhart and Crookston 2003; Western Sierras Variant). These corrections and revised results are explained in Levine et al. (2019). Adding the bark increased the mean DSHto-DBH ratio to 1.13 for the 9,075 conifer trees included in this analysis (hardwoods, which comprise $2 \%$ of the total trees in the study, were not affected by this correction). We used the corrected taper equations including bark for all analyses in this reply.

Our corrected DSH-to-DBH ratio was still considerably less than the 1.23 result reported by B\&W. Their ratio is derived from unpublished data collected in Arizona that does not account for differences in allometry among tree species. B\&W also raise concerns about the appropriateness of using taper equations to calculate 
DSH from DBH. They quote Biging (1984:1106): "the inability to characterize the lower portion of a tree with significant butt swelling," implying that these taper equations are inaccurate. However, the section in Biging (1984) continues with a description of methods from four references that do track stem form, including butt swelling. Moreover, B\&W did not acknowledge the basic premise of Biging (1984), which was to report the successful development of taper equations for the major conifer species in the Sierra Nevada. The equations from Wensel and Olson (1995) that we used to calculate DSH from DBH further refine the taper models presented in Biging (1984) for the species in our study.

\section{Simulated sampling regime}

$\mathrm{B} \& \mathrm{~W}$ contend that the sampling regime simulated by Levine did not capture unique properties of the MHVD approach. In the GLO data, some points (section corners) sampled the four nearest neighbors $(4 \mathrm{nn})$ and some (quarter corners) only the two nearest neighbors (2nn). The MHVD pools both $4 \mathrm{nn}$ and $2 \mathrm{nn}$ points. However, the alternative PDEs included in Levine did not account for such pooled sampling. Thus, in order to compare methods, we evaluated $4 \mathrm{nn}$ and $2 \mathrm{nn}$ sampling schemes separately. To address B\&W's concerns, in this response we present and evaluate new simulations that incorporate the pooling method of $\mathrm{B} \& \mathrm{~W}$ for the MHVD.

\section{Calculation of mean neighborhood density}

$\mathrm{B} \& \mathrm{~W}$ take issue with the calculation of mean neighborhood density (MND) in the simulations presented in Levine. A unique feature of the MHVD is the estimation of the mean Voronoi area (MVA) of each tree based on diameter adjusted by the MND. Rather than assigning an MND to each individual point in these simulations, we used neighborhood estimates of MND. Specifically, MND was calculated for 21 regularly spaced section corners $(4 \mathrm{nn})$ in every 4.0-ha stand. When calculating MHVD for a point, we used the MND from the nearest section corner. This approach ensured that each tree in the stand had only one estimate of MND and thus only one estimate of MVA. Nevertheless, in the analyses included in this review, we calculated point-specific MND.

\section{New simulations}

We used the stem maps from Levine for six mixedconifer and dry pine forests in the Sierra Nevada and Sierra de San Pedro Martír to evaluate the performance of the MHVD taking into account the critiques of B\&W, as detailed above. Sites are abbreviated PLUM, YOSE, TEAK, META, BRID, and GRAN, and range in density from 784 trees/ha (PLUM) to 159 trees/ha (GRAN).
Each stand was 4.0 ha in area and all the live trees $\geq 9.5 \mathrm{~cm} \mathrm{DBH}$ were included. Given that all trees were mapped, we calculated the true Voronoi area (true VA) for every tree. For full site descriptions, see Levine.

We relied on Monte Carlo simulations to estimate the central tendency and variation in the point density estimates. For each realization, we applied a six-point sampling simulation as specified by B\&W. Specifically, this sampling included two section corners $(4 \mathrm{nn})$ and four quarter corners $(2 \mathrm{nn})$ for a total of 16 witness trees (Appendix S1: Fig. S1). MND was calculated for each point individually, as described above. All calculations were based on the corrected estimates of DSH. For each stand, we ran 100 realizations where the six--point sampling scheme was moved systematically throughout the stand but maintained the spacing between points (Appendix S1: Fig. S1). Buffers were applied so that all trees had true VA polygons calculated with neighbors on all sides. We used the species-specific regression equations detailed in Baker (2014) to estimate the crown radius from the DSH and then the MVA of each witness tree. As noted above, the MVA was calculated using the point-specific calculation of MND.

We found the median MHVD estimate of tree density was substantially greater than the true density in all six stands (Fig. 1). In terms of relative error (simulated density/observed density), the median of the six-point sampling scheme ranged from 1.93 (PLUM) to 3.82 (META; Appendix S1: Table S1). TEAK was the only site of six where the lower bound of the $95 \%$ CI overlapped with the true density (Appendix S1: Table S1), though the median estimate was $96 \%$ higher than the true density (Fig. 1).

To understand the source of the error, we compared the MVA to true VA for all trees in the six stands (Fig. 2). As noted above, when the MND is calculated for each point, multiple estimates of MVA for a given tree are produced in our simulations. Thus, for our comparison, we report the estimated Voronoi area as the mean MVA for the trees with more than one value (Fig. 2). We also calculated the correlation with MVA and the true Voronoi area for all 1,600 observations (i.e., multiple MVA observations for the same trees; Appendix S1: Fig. S2). For every stand, the estimated Voronoi area underestimated the true VA (Fig. 2). This result was consistent whether all 1,600 witness trees were included in the regression (Appendix S1: Fig. S2) or if the MVA was averaged for duplicate trees (Fig. 2).

We quantified the relationship between the true VA and the mean point-to-tree distance of each of the 1,600 witness trees in the simulations at each site. We found that the mean point-to-tree distance is a reasonable predictor of Voronoi area, regardless of a tree's size (Appendix S1: Fig. S3; $r^{2}$ for the six sites ranging from 0.24 to 0.45 ). In fact, MND explained nearly as much variance as MVA (Fig. $2 ; r^{2}$ ranging from 0.25 to 0.55 ). This relationship 


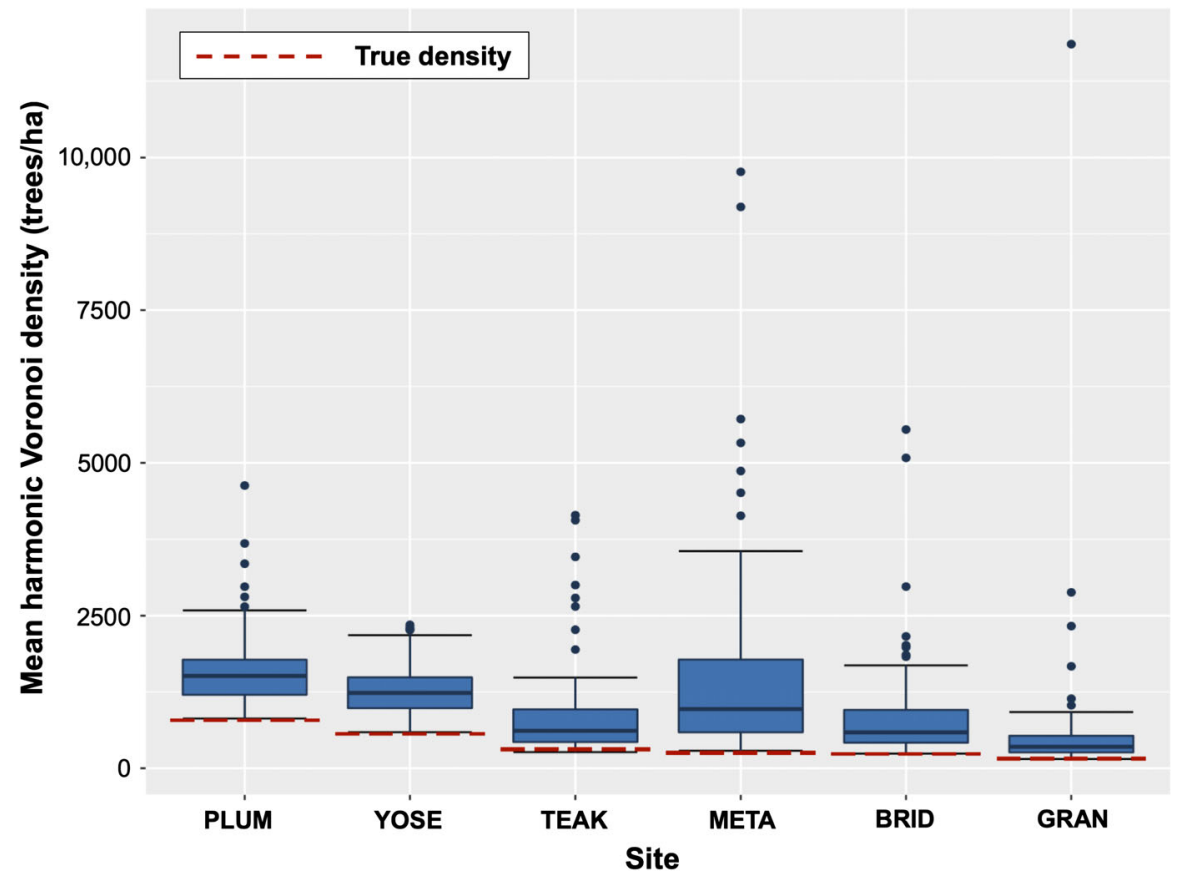

FIG. 1. Estimate of density (trees/ha) in fully censused, mapped 4.0-ha plots calculated using the mean harmonic Voronoi density (MHVD) approach based on a six-point sampling scheme (two section corners and four quarter corners, 16 witness trees total). Median and interquartile ranges are derived from 100 simulation runs. The midline of the boxplot represents the median of the data, the upper and lower limits of the box represent the third and first quartile of the data, and the whiskers represent the $1.5 \times$ interquartile range from the third and first quartile. The true density of each plot is represented by the dashed red line.

between tree area and point-to-tree distances is precisely the relationship on which traditional point-based PDEs such as the Cottam, Pollard, and Morisita are based. In other words, the explanatory power of the MHVD estimator (as shown in Fig. 2) is more a function of MND than the predicted size of the trees' crowns.

The scaling factor (MND) used by Williams and Baker (2011) in Voronoi area equations is identical to the Cottam plotless density estimator for four-tree (4nn) corners (Cottam and Curtis 1956). The same MND equation, however, is incorrect at two-tree ( $2 \mathrm{nn}$ ) corners and overestimates density by a factor of two (Cogbill et al. 2018). Moreover, regardless of the number of trees sampled at a point, the application of the Cottam estimator to single trees (Shanks variant), as used by B\&W, greatly overestimates the scaling factor compared to larger pools (Cogbill et al. 2018). In addition, the $4 \mathrm{nn}$ and $2 \mathrm{nn}$ sampling have different responses to nonrandom or heterogeneous dispersion (Cogbill et al. 2018). Thus, the Voronoi areas of at least one-half the trees are wrongly scaled and the pooling of $4 \mathrm{nn}$ and $2 \mathrm{nn}$ corners incorporates many VAs that are underestimated. The mixing of disparate densities based on MND scaling confounds the calculation of MVA. As reported in B\&W (Appendix S1: pg. 21), the difference between $4 \mathrm{nn}$ (569 trees/ha) and 2nn (1036 trees/ ha) density estimates for YOSE by the MHVD method in itself indicates the inconsistency inherent in the method. The other three PDE methods did not show a discrepancy in density estimates between $2 \mathrm{nn}$ only and 4nn only sampling (see Levine Appendix S1). In an independent study, a comparison of PDEs found the Voronoi density estimate (Williams and Baker 2011) for the Blue Mountains of Oregon "unreliable" and more than twice that independently estimated by either Cottam or Morisita estimators alone (Johnston et al. 2018).

To further assess the relevance of tree size, we reran our simulations for YOSE using a DSH-to-DBH ratio of 1.23, the unpublished constant provided by B\&W. We used the same six-point pooling described above, with 100 realizations. We obtained a median density of 1,182 trees/ha (lower CI 577 trees/ha, upper CI 2,138 trees/ha). This median is 2.1 times higher than the true density, and the lower bound of the CI does not overlap the true mean of 562 trees/ha. To replicate the density of 670 trees/ha for YOSE that B\&W obtained from their analysis, we had to raise the DSH-to-DBH ratio to 4.75 , which of course is biologically impossible.

The B\&W reanalysis of the published YOSE data using a modification of our published script relied on an improvised and inconsistent approach. Their re-analysis only adjusts the DSH-to-DBH ratio and the sample size (i.e., six points). It does not account for the other criticisms leveled by B\&W. For example, their implementation at the YOSE site does not capture the distribution and spacing of the six-corner pool nor does it calculate point-specific estimates of MND. Their critique of our 


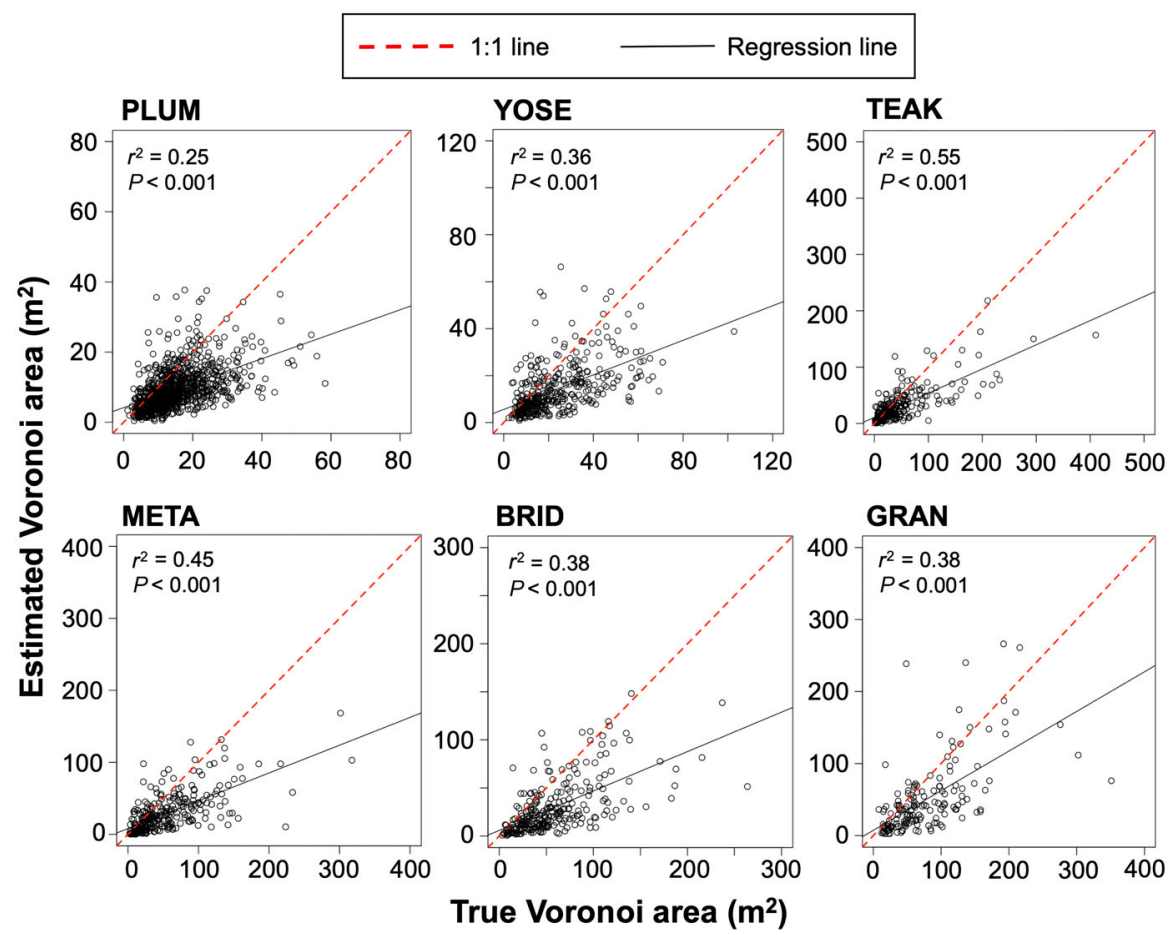

FIG. 2. The relationship between the true and estimated Voronoi area (VA) for the witness trees in each of the fully censused, mapped 4.0-ha stands. The $r^{2}$ value and the $P$ value of the site-specific regression are shown in each panel. When the same tree was sampled in more than one simulation run, the mean of the tree's estimated VA is used.

MHVD deconstruction is similarly incomplete. Using data from PLUM that we shared privately with Baker and Williams prepublication, they identified two sets of six points where they deduced that the MND was correctly estimated. Using results from these two subjectively chosen samples, they argue general principles. Neither of these critiques are robust. Furthermore, their ad hoc methods were not necessary. We shared our manuscript pre-publication with Baker and Williams and invited comments. Beyond the corrections posted in Baker (2017), they chose not to respond despite repeated invitations. Moreover, they have never publicly posted their GLO data or code for others to evaluate, nor have they published or provided the species-specific data from which they obtained their regression equations for estimating crown radius and VA. As we have shown here, we are willing to share our data and code and are able to refine our simulations to better understand the performance of established and new PDEs.

\section{Response to Qualitative Concerns}

\section{Spatial scale of analysis}

B\&W assert that the 4.0-ha plots used in Levine are too small to properly test the performance of the MHVD. However, the statistical foundation of the MHVD is independent of scale. Williams and Baker
(2011) provide a thorough review of the theory underpinning Voronoi-based estimators of tree density. Indeed one of the main advantages of the Voronoi-based estimator noted by Williams and Baker (2011) is its indifference to sampling intensity and spatial variability. Specifically, they cite Delincé (1986) who showed indistinguishable error rates for sampling intensities (points/ total number of trees $\times 100 \%$ ) from $0.6 \%$ to $3 \%$ and spatial variation from none (regular pattern) to high (aggregated pattern). Moreover in the classic study by Cottam and Curtis (1956) of the Cottam PDE, the sampling intensities were even higher (17\% to $33 \%)$. Levine included a wide range of sampling intensities from 3 points per stand to 1,000. The performance of the MHVD was relatively insensitive to sampling intensity (e.g., Tables A7 and A8 in Levine).

A specific concern related to spatial scale is the dearth of independent observations in the simulations (B\&W Appendix S1: pg. 22). The issue seems to be the nonrandom distribution of trees in the stands, a fact that Levine noted in the point pattern analyses included in the supplementary material (Levine Fig. A1). Indeed, this fact guided the choice of analysis, namely Monte Carlo simulations to generate confidence intervals for estimates of tree density. As noted in the landmark review of resampling methods in ecology (Crowley 1992), an advantage of the Monte Carlo method over standard parametric approaches is the relaxation of the assumption of 
statistically independent data (Crowley 1992, Table 1). The Monte Carlo simulations used by Levine follow established practice for comparing the accuracy and precision of PDEs (Engeman et al. 1994, White et al. 2008, Hanberry et al. 2011).

\section{Geographical location of sites}

$\mathrm{B} \& \mathrm{~W}$ note that three of the stands included in Levine were outside of the study area defined in Baker (2014). They argue that results from these stands are inappropriate tests of MHVD performance because they are "dominated by different trees" from the ones sampled in Baker (2014). Of the three stands outside the study area (BRID, GRAN, META), only BRID included a substantial number of trees (226 out of 944 individuals) without a species-specific crown radius and Voronoi equations included in Baker (2014, Table D1). For META, all the individuals were included in Table D1; for GRAN, only six trees out of 635 were not included. In the absence of species-specific equations, Levine used the most appropriate general equations (i.e., "Fir," "Pine," or All species pooled). Furthermore, MHVD performed only marginally better in the three Sierra Nevada stands that have been subject to $100+\mathrm{yr}$ of fire exclusion. In both Levine et al. (2019: Tables 2 and 3) and here (Appendix S1: Table S1), the MHVD consistently overestimates tree density.

\section{Neglect of corroborating evidence}

$\mathrm{B} \& \mathrm{~W}$ argue that Levine overlooked published evidence that validates MHVD estimates of tree density against historical sources. This criticism misses the point of the Levine study. As noted earlier, our purpose was to investigate the performance of an array of PDEs, not to critique the MHVD specifically. In addition, the historical comparisons are irrelevant given our design. By comparing PDEs in plots where all stems were mapped, we directly calculated estimated densities and Voronoi areas from data and then compared the estimated densities against plot densities based on complete censuses. With this robust and powerful design, there is no need to refer to historical evidence.

\section{Conclusion}

Based on this new analysis of the data, we confirmed the two main conclusions of Levine with respect to the MHVD. First, the MHVD overestimates tree density by a range of $24-667 \%$ in six mapped stands (Appendix S1: Table S1). These results were based on simulations that used the corrected DSH values and sampling schemes recommended by B\&W. Second, we conclusively show that this bias is due to a consistent underestimation of Voronoi area relative to the true VA (Fig. 2). As noted in Levine and elaborated here, the problem with the MHVD is two- fold. The allometric equations used to estimate Voronoi area from DSH have relatively little independent explanatory power. Most of the predictive power is embedded in the MND (Appendix S1: Fig. S3). The equation used by Baker (2014) to calculate MND (see equation in Table 2 in Williams and Baker 2011) is not corrected for the number of neighboring trees despite the well-documented dependence on sample size (e.g., Cottam and Curtis 1956, Cogbill et al. 2018). As a result, the $2 \mathrm{nn}$ points underestimate Voronoi area (Appendix S1: Fig. S3), and thus overestimate tree density, by systematically underestimating point-to-tree distances (Fig. 3 in Levine).

\section{Literature Cited}

Baker, W. L. 2012. Implications of spatially extensive historical data from surveys for restoring dry forests of Oregon's eastern Cascades. Ecosphere 3:23.

Baker, W. L. 2014. Historical forest structure and fire in Sierran mixed-conifer forests reconstructed from General Land Office survey data. Ecosphere 5:79.

Baker, W. L. 2017. Erratum: Historical forest structure and fire in Sierran mixed-conifer forests reconstructed from General Land Office survey data. Ecosphere 8:Article e01665.

Baker, W. L., and M. A. Williams. 2018. Land-surveys show regional variability of historical fire regimes and structure of dry forests of the western USA. Ecological Applications 28:284-290.

Biging, G. S. 1984. Taper equations for second-growth mixed conifers of Northern California. Forest Science 30:1103-1117.

Bourdo, E. A. 1956. A review of the General Land Office survey and of its use in quantitative studies of former forests. Ecology 37:754-768.

Cogbill, C. V., J. Burk, and G. Motzkin. 2002. The forests of presettlement New England, USA: spatial and compositional patterns based on town proprietor surveys. Journal of Biogeography 29:1279-1304.

Cogbill, C. V., A. L. Thurman, J. W. Williams, J. Zhu, D. J. Mladenoff, and S. J. Goring. 2018. A retrospective on the accuracy and precision of plotless forest density estimators in ecological studies. Ecosphere 9:e02187.

Cottam, G., and J. T. Curtis. 1956. The use of distance measures in phytosociological sampling. Ecology 37:451-460.

Crowley, P. H. 1992. Resampling methods for computationintensive data analysis in ecology and evolution. Annual Review of Ecology and Systematics 23:405-447.

Delincé, J. 1986. Robust density estimation through distance measurements. Ecology 67:1576-1581.

Engeman, R. M., R. T. Sugihara, L. F. Pank, and W. E. Dusenberry. 1994. A comparison of plotless density estimators using Monte Carlo simulation. Ecology 75:1769-1779.

Goring, S. J., et al. 2016. Novel and lost forests in the Upper Midwestern United States, from new estimates of settlementera composition, stem density, and biomass. PLoS ONE 11: e0151935.

Hanberry, B. B., S. Fraver, H. S. He, J. Yang, D. C. Dey, and B. J. Palik. 2011. Spatial pattern corrections and sample sizes for forest density estimates of historical tree surveys. Landscape Ecology 26:59-68.

Hanberry, B. B., B. J. Palik, and H. S. He. 2012. Comparison of historical and current forest surveys for detection of homogenization and mesophication of Minnesota forests. Landscape Ecology 27:1495-1512. 
Johnston, J. D., C. J. Dunn, M. J. Vernon, J. D. Bailey, B. A Morrissette, and K. E. Morici. 2018. Restoring historical forest conditions in a diverse inland Pacific Northwest landscape. Ecosphere 9:e02400.

Keane, R. E., R. A. Loehma, L. M. Holsinger, D. A. Falk, P. Higuera, S. M. Hood, and P. F. Hessburg. 2018. Use of landscape simulation modeling to quantify resilience for ecological applications. Ecosphere 9:e02414.

Kronenfeld, B. J., and Y.-C. Wang. 2007. Accounting for surveyor inconsistency and bias in estimation of tree density from presettlement land survey records. Canadian Journal of Forest Research 37:2365-2379.

Levine, C. R., C. V. Cogbill, B. M. Collins, A. J. Larson, J. A. Lutz, M. P. North, C. M. Restaino, H. D. Safford, S. L. Stephens, and J. J. Battles. 2017. Evaluating a new method for reconstructing forest conditions from General Land Office survey records. Ecological Applications 27:1498-1513.

Levine, C. R., C. V. Cogbill, B. M. Collins, A. J. Larson, J. A. Lutz, M. P. North, C. M. Restaino, H. D. Safford, S. L. Stephens, and J. J. Battles. 2019. Errata for evaluating a new method for reconstructing forest conditions from Genera Land Office survey records. Ecological Applications 29:158.

Maxwell, R. S., A. H. Taylor, C. N. Skinner, H. D. Safford, R. E. Isaacs, C. Airey, and A. B. Young. 2014. Landscape-scale modeling of reference period forest conditions and fire behavior on heavily logged lands. Ecosphere 5:1-28.

Morisita, M. 1957. A new method for the estimation of density by spacing method applicable to nonrandomly distributed populations. Physiology and Ecology 7:134-144. English translation by USDA Division of Range Management 1960. http://math.hws.edu/ mitchell/Morisita1957.pdf

North, M., P. Stine, K. O'Hara, W. Zielinski, and S. Stephens, 2009. An ecosystems management strategy for Sierra MixedConifer forests. General Technical Report PSW-GTR-220. USDA Forest Service, Pacific Southwest Research Station, Albany, California, USA.

Paciorek, C. J., S. J. Goring, A. L. Thurman, C. V. Cogbill, J. W. Williams, D. J. Mladenoff, J. A. Peters, J. Zhu, and J. S McLachlan. 2016. Statistically-estimated tree composition for the Northeastern United States at Euro-American settlement. PLoS ONE 12:e170835.

Pollard, J. H. 1971. On distance estimators of density in randomly distributed forests. Biometrics 27:991-1002.

Reinhart, E. D., and N. L. Crookston. 2003. The fire and fuels extension to the forest vegetation simulator. General Technical Report RMRS-GTR-116. p. 209. U.S. Department of Agriculture, Forest Service, Rocky Mountain Research Station, Ogden, Utah, USA.

Rhemtulla, J. M., D. J. Mladenoff, and M. K. Clayton. 2009. Historical forest baselines reveal potential for continued carbon sequestration. Proceedings of the National Academy of Sciences USA 106:6082-6087.

Schulte, L. A., and D. J. Mladenoff. 2001. The original US public land survey records: their use and limitations in reconstructing presettlement vegetation. Journal of Forestry 99:5-10.

Stephens, S. L., B. M. Collins, E. Biber, and P. Z. Fulé. 2016. U.S. federal fire and forest policy: emphasizing resilience in dry forests. Ecosphere 7:e01584.

Wensel, L. C., and C. M. Olson. 1995. Tree taper models for major commercial California conifers. Hilgardia 62:1-16.

White, N. A., R. M. Engeman, R. T. Sugihara, and H. W. Krupa. 2008. A comparison of plotless density estimators using Monte Carlo simulation on totally enumerated field data sets. BMC Ecology 8:1-11.
Williams, M. A., and W. L. Baker. 2011. Testing the accuracy of new methods for reconstructing historical structure of forest landscapes using GLO survey data. Ecological Monographs $81: 63-88$

CARrie R. Levine

Department of Environmental Science and Policy, University of California, Davis, One Shields Avenue, Davis, California 95616

USA

E-mail: crlevine@berkeley.edu

Present address: Conservation Science Partners, Inc., 11050 Pioneer Trail, Truckee, California 96161 USA

Charles V. Cogbill

Harvard Forest, Harvard University, 324 North Main Street, Petersham, Massachusetts 01366 USA

Brandon M. Collins

USDA Forest Service, Pacific Southwest Research Station, 1731 Research Park Drive, Davis, California 95618 USA and Center for Fire Research and Outreach, College of Natural Resources, University of California, Berkeley, California 94720-3114 USA

ANDREW J. LARSON

Department of Forest Management, University of Montana, 32 Campus Drive, Missoula, Montana 59812 USA

JAmES A. Lutz iD

S. J. \& Jessie E. Quinney College of Natural Resources, Utah State University, 5230 Old Main Hill, Logan, Utah 84322-5230 $U S A$

MaLCOLM P. NORTH

USDA Forest Service, Pacific Southwest Research Station, 1731 Research Park Drive, Davis, California 95618 USA and Department of Plant Sciences, University of California, Davis, One Shields Avenue, Davis, California 95616 USA

Christina M. Restaino

Tahoe Regional Planning Agency, P.O. Box 5310, Stateline, Nevada 89449 USA

Hugh D. SAFFord

Department of Environmental Science and Policy, University of California, Davis, One Shields Avenue, Davis, California 95616 USA and

USDA Forest Service, Pacific Southwest Region, 1323 Club

Drive, Vallejo, California 94592 USA

Scott L. STephens

John J. BATTLES (iD)

Department of Environmental Science, Policy, and Management, University of California, 130 Mulford Hall, Berkeley, California 94720-3114 USA

Manuscript received 1 November 2018; revised 20 May 2019; accepted 14 June 2019. Corresponding Editor: Andrew O. Finley. 


\section{SUPPORTING INFORMATION}

Additional supporting information may be found online at: http://onlinelibrary.wiley.com/doi/10.1002/eap.1968/full 